\title{
Examination of a tropospheric ozone control methodology from the explicit representation of POCPs across varying temporal and continent spatial domains
}

\author{
$\underline{\text { S.H.M. Lam }}{ }^{\mathrm{a}, \mathrm{b}}$, S. M. Saunders ${ }^{\mathrm{a}}$, H. R. Cheng ${ }^{\mathrm{c}, \mathrm{d}}$, H. Guo ${ }^{\mathrm{d}}$ \\ ${ }^{a}$ School of Chemistry and Biochemistry, University of Western Australia, Perth, W. Australia \\ ${ }^{b}$ Pacific Environment Limited, Level 1, Suite 3, 34 Queen Street, Perth W. Australia \\ ${ }^{c}$ Department of Environmental Engineering, School of Resources and Environmental Science, Wuhan \\ University, China \\ ${ }^{d}$ Department of Civil and Environmental Engineering, the Hong Kong Polytechnic University, Hong Kong \\ Email:Sean.Lam@pacific-environment.com
}

\begin{abstract}
Ozone is an internationally recognized criteria air pollutant, and remains a major concern despite more than 25 years of regulation at the national level. A method developed by Derwent and coworkers (1996, 1998) and initially applied in the United Kingdom (UK), was to define POCPs (photochemical ozone creation potentials), as a means of ranking, in a semi-quantitative way, the contributions of different non-methane volatile organic compounds (VOCs) to ozone formation.

To develop an understanding of the differences in high ozone formation in other regions of the world, subsequent modeling studies determined POCPs for the USA and Asia (The Pearl River Delta (PRD), China and Hong Kong (HK)), each region with different VOC and NOx emissions and characteristics. In this study POCP's are calculated on the Australian continent, for the city of Perth, of notably lower levels of air pollution than all previous studies. The POCP values were generally found to be lower than those determined previously in the UK, USA and Asia. An assessment is made of the similarities and differences between the four continents, first by VOC group classification and then by analyzing the ranking of the VOC in terms of the highest 50 POCP values from across all studies.
\end{abstract}

Despite different geographic locations, meteorology and emissions (VOC and NOx), leading to differing temporal peak ozone duration and concentration at the receptors, a number key VOC were found to he high ozone contributors across all locations. This shows a dominance of alkene and aromatic compounds, and 25 of the 50 VOC with the highest POCP values are common across the region studied. These VOC are ethene, propene, isoprene, the butenes and pentenes, and though some of the aromatic compounds differed between the regions, the trimethyl benzenes were also consistently highly ranked. They are identified as key target VOC for consideration in emissions reduction strategies. Other VOC that influence ozone in specific regions were found to generally rank low in the highest 50 POCP groups, however the region specific ranking of formaldehyde, acetaldehyde and diethyl ether can be inferred as significant from their higher ranking positions in HK, Perth and the USA, should also be taken into consideration in targeted reductions.

Given the commonality of the identified key VOC with the much more highly polluted airsheds also shows that the determination of POCP's for Perth has provided insightful intercomparisons, using the POCP ranking from across the regions, to identify key anthropogenic emitted VOC, that will most likely continue to be significant contributors to high ozone events in Perth, as the region experiences high population and development growth, with a significantly increasing burden on the regions VOC and NOx emissions.

The study provides further support that the POCP methodology has considerable potential for application in policy development. The need for practical abatement policies is substantial with the growing need to redress the large increase in the occurrence of episodic high ozone concentrations in many rapidly developing regions of the world.

Keywords: Photochemical Ozone Creation Potentials (POCPs), Volatile Organic Compounds (VOC), photochemical model 


\section{INTRODUCTION}

Despite air quality guidelines being in place for more than 2 decades, the continued growth in rapidly developing regions of the world means that air pollution remains a current major global concern. There are serious risks to health from exposure to air pollutants in many regions and growing evidence of the association between ambient photochemical oxidants $\left(\mathrm{O}_{3}\right.$ and $\left.\mathrm{NO}_{2}\right)$ and a wide range of adverse health effects. These range from acute respiratory and cardiopulmonary symptoms to cancer and premature death (e.g. Srebot et al., 2009; WHO, 2004, 2006). A recent study found that annually polluted air causes over 6 million deaths worldwide (Lim et al., 2013). Symptoms have been linked to various constituents of photochemical smog, however it is now widely accepted that ozone and suspended particulate matter are the cause for greatest concern (Ostro, 2004; USEPA, 2006). This study extends the methodologies aimed at reducing the occurrence of high ozone events, and hence the associated health impacts.

Formation of high levels of ambient $\mathrm{O}_{3}$, in excess of the current WHO guideline $\left(100 \mu \mathrm{g} / \mathrm{m}^{3}\right.$ for an 8 -hour average, WHO, 2006) is highly complex due to the non-linear relationship between $\mathrm{O}_{3}$ and its known precursors; many hundreds of non-methane volatile organic compounds (VOCs) and $\mathrm{NO}_{x}\left(\mathrm{NO}\right.$ and $\left.\mathrm{NO}_{2}\right)$ (Sillman, 1999). Hence region specific studies, with assessment of emissions and reactivity are needed do develop appropriate regional $\mathrm{O}_{3}$ control strategies. Computational models are one of the tools used in developing such strategies (Derwent et al., 1998, Evtyungina et al., 2007, Walker et al., 2009). A method proposed by Derwent and co-workers (Derwent et al., 1996, 1998) and initially applied in the United Kingdom, was to simulate multi-day (96 hour) peak $\mathrm{O}_{3}$ development and derive POCPs (photochemical ozone creation potentials), as a means of ranking, in a semi-quantitative way, the contributions of different VOCs to the ozone formation. Developing an understanding of the key drivers since the 1990s has enabled emission control strategies to contribute to reduced $\mathrm{O}_{3}$ episodes in the region (Jenkin, 2008).

By definition a POCP for a specific VOC is not an absolute value but will vary depending upon the model employed and other parameters used in its calculation (Derwent et al., 1996). To gain a better understanding of differences in high ozone formation in other regions of the world, subsequent modeling studies have determined POCPs for single day (24 hour) peak $\mathrm{O}_{3}$ in the USA (Derwent et al., 2001) and multiple peak $\mathrm{O}_{3}$ days (72 hour) in the Pearl River Delta (PRD) (Cheng et al., 2010) and Hong Kong (HK) (Cheng et al., 2013), each region with different VOC and NOx emissions and meteorological characteristics. This type of modeling assesses 'typical' scenarios of high ozone events on the timescale of hours to days, in the different global regions, with the aim to guide reductions in the occurrence of such events.

There has been a significant increase of episodic high ozone levels in rapidly developing regions of the world, such as the PRD and Beijing in China, and other global megacities. However the issue is not only confined to these regions of known poor air quality. Western Australia (WA) had a low population density, currently 2.2 million, and experiences poor air quality on only a few days each year (DEC, 2005, 2012b). However it has significant population growth currently at 78,000 a year (ABS, 2013), and the increasing pressure on vehicle load will add significant burden to the regions VOC and NOx emissions. Understanding the drivers for photochemical air pollution in the region, will aid future management strategies. In this study a near-explicit photochemical model coupled with the latest version of the MCM(v3.1 extended) has been tailored for Perth, WA, and POCP's calculated for the region. An assessment is then made of the similarities and differences in the VOC rankings between the four continents (Europe, USA, Asia and Australia) in terms of their potential to form ozone.

\section{PHOTOCHEMICAL MODEL FOR PERTH}

\subsection{Model description}

The model developed for this work, follows the same construct as our previous studies (Cheng et al., 2010, 2013), adapted here for the local conditions in Perth. The Lagrangian box model simulates the complex photochemistry within a well-mixed boundary layer air parcel, as described previously (e.g. Derwent et al., 1996, 1998). Briefly each species, $C i$ defined in the model, is represented by a differential equation (1)

$$
\frac{d C i}{d t}=P i-L i . C i-\frac{V C i}{h}-(C i-B i) \frac{d h}{d t}
$$

Where $C i$ is the species concentration in the air parcel. $P$ is the instantaneous production and $L$ the instantaneous loss rate by photochemistry. $V$ is the species dependent dry deposition rate. $h$ is the timedependent boundary layer height (blh), Ei is the local emission rate from pollution sources and $B i$ the background concentration of the emitted and stable species above the boundary layer, input the following 
morning as their concentration from the previous evening, and entrained as the boundary layer rises. Aloft concentrations for the first night are taken as the initial concentrations.

The blh varies from $300 \mathrm{~m}$ at night to $1200 \mathrm{~m}$ during the daytime. The horizontal dimensions of the air parcel are $10 \times 10 \mathrm{~km}$ centered in Perth, encompassing Kwinana to the south, Yanchep to the north and Rolling Green to the east. It picks up hourly emissions of anthropogenic and biogenic VOCs, $\mathrm{CO}, \mathrm{NO}_{\mathrm{x}}, \mathrm{SO}_{2}$ and undergoes photochemical and deposition processes. The anthropogenic emission inventory (EI) employed was retrieved from the WA section of the National Pollutant Inventory (NPI, 2007), for the Perth region, $40 \mathrm{x}$ $70 \mathrm{~km}$, gridded over $3 \times 3 \mathrm{~km}$ cells. The distribution of the 139 primary emitted VOC is made using the compound categories and sectors defined in the Perth photochemical smog study (Cope and Ischtwan, 1995). The biogenic VOC (BVOC) emissions are estimated from the only available data sources DEC (NPI, 2007, and SKM, 2003). Only emissions of isoprene, $\alpha$ - and $\beta$-pinene were used as these species accounted for the majority of the total BVOC emission in the region. The emissions are scaled to the $10 \mathrm{x} 10 \mathrm{~km}$ grid and represented as hourly emission rates in a bimodal format as a reflection of increased emissions in both the early morning and afternoon peak periods.

As a simple box model there is no treatment of vertical or horizontal dispersion, the VOCs are assumed well mixed throughout. Hence, the idealized simulation will not capture the influence of any short-term perturbations from local sources, but rather simulates the peak ozone that could be generated in the wellmixed box.

\subsection{Master Chemical Mechanism and numerical methods}

The chemical mechanism and associated rate coefficients (extended version of the MCM v3.1) describes the complete photochemical oxidation of methane and 139 non-methane VOCs. It can be accessed via the University of Leeds website (http://mcm.leeds.ac.uk /MCM). Based on the geographic location of Perth the summertime dependence of the photolysis rate coefficients were calculated to be representative of the solar intensity experienced during $\mathrm{O}_{3}$ episodes in the region. Using a similar approach to Pinho et al. (2009), the photolysis coefficients were calculated using the photon flux determined from the Tropospheric Ultraviolet and Visible Radiation (TUV) Model (Madronich, 2012). FACSIMILE software (Curtis and Sweetenham, 1987, v4 MCPA, 2011) was used to integrate the model system of 5,900 differential equations; with integration output set each hour.

\subsection{Meteorological and air quality data}

The main observational data used to define initial conditions and evaluate model performance were taken at the Caversham DEC-AQMS location (latitude $22^{\circ} 43 \mathrm{~N}$, longitude $113^{\circ} 33 \mathrm{E}$ ). This site experiences elevated ozone levels associated with the meteorological conditions leading to the development of high ozone concentrations in the region. The chemical species measured at the AQMS site include $\mathrm{O}_{3}, \mathrm{CO}, \mathrm{SO}_{2}, \mathrm{NO}_{\mathrm{x}}$. The initial mixing ratios for the majority of VOC species in the model are set to $0.5 \mathrm{ppb}$ and, for a small number of species, initial mixing ratios are set based on available measurements (DEC, 2012a, Zardin, 2012), as follows: $\mathrm{HCHO}$ at $1 \mathrm{ppb}, \mathrm{CH}_{3} \mathrm{CHO}$ at $2 \mathrm{ppb}, \mathrm{CH}_{3} \mathrm{COCH}_{3}$ at $1 \mathrm{ppb}, \mathrm{CH}_{3} \mathrm{OH}$ at $4 \mathrm{ppb}, \mathrm{C}_{5} \mathrm{H}_{8}$ at $2 \mathrm{ppb}$, toluene at $1 \mathrm{ppb}$ with $\mathrm{NOx}$ at $10 \mathrm{ppb}, \mathrm{CO}$ at $150 \mathrm{ppb}, \mathrm{CH}_{4}$ at $1790 \mathrm{ppb}$ and $\mathrm{O}_{3}$ at $20 \mathrm{ppb}$.

\section{RESULTS AND DISCUSSION}

\subsection{Comparison of simulated and observed photochemical $\mathrm{O}_{3}$ episodes}

In Perth high $\mathrm{O}_{3}$ (hourly average $>100 \mathrm{ppb}$ ) does not increase and develop over a number of days, but rather gives a single day occurrence. Hence a simulation of 24 hours is sufficient to capture the $\mathrm{O}_{3}$ episode characteristics of the region. The base case model simulated peak $\mathrm{O}_{3}$ well attaining levels in the afternoon $\sim 110 \mathrm{ppb}$, as well as the low level of NOx ( 2 ppb), which sits between the peak $\mathrm{O}_{3}$ days of $>100$ and $<130$ ppb observed in the region for the few days between 2004 - 2010 (DEC, 2005, 2012b)

\subsection{Photochemical ozone creation potentials (POCPs) of individual VOCs}

The POCP for each VOC was calculated after running a separate 24 hour model experiment and each had the same mass increment of an individual VOC emission above the base case $(6.8 \%$ of the total integrated VOC emission, as in previous studies, Cheng et al., 2010, 2013) (Table 1). The POCP is calculated relative to that as a result of an identical increase in emission (on a mass basis) for ethene (reference VOC), equation (2).

$$
\text { POCP }_{i}=\frac{\text { Ozone increment with the ith VOC }}{\text { ozone increment with the ethene }} \times 100
$$


Table 1. POCP values for Perth

\begin{tabular}{|c|c|c|c|c|c|}
\hline & $\begin{array}{c}\text { POCP } \\
\text { Perth, } \\
\text { WA }\end{array}$ & & $\begin{array}{c}\text { POCP } \\
\text { Perth, } \\
\text { WA }\end{array}$ & & $\begin{array}{c}\text { POCP } \\
\text { Perth, } \\
\text { WA }\end{array}$ \\
\hline \multirow[t]{2}{*}{ Hydrocarbons } & & & & Alcohols and Glycols & \\
\hline & & Aromatic VOC & & Methanol & 7 \\
\hline Alkanes & & Benzene & -6 & Ethanol & 9 \\
\hline Ethane & 1 & Toluene & 8 & n-Propanol & 8 \\
\hline Propane & 6 & o-Xylene & 24 & i-Propanol & 14 \\
\hline n-Butane & 10 & $\mathrm{~m}$-Xylene & 34 & n-Butanol & 2 \\
\hline i-Butane & 21 & p-Xylene & 16 & 2-Butanol & \\
\hline n-Pentane & 6 & Ethylbenzene & 2 & 2-Methyl-1-propanol & 18 \\
\hline i-Pentane & 17 & Propylbenzene & 0 & 2-Methyl-2-propanol & 22 \\
\hline n-Hexane & 3 & i-Propylbenzene & 3 & 3-Pentanol & 9 \\
\hline 2-Methylpentane & 10 & 1,2,4-Trimethylbenzene & 69 & 2-Methyl-1-butanol & 13 \\
\hline 3-Methylpentane & 14 & 1,3,5-Trimethylbenzene & 92 & 3-Methyl-1-butanol & 31 \\
\hline 2,2-Dimethylbutane & 3 & o-Ethyl toluene & 5 & Cyclohexanol & 31 \\
\hline 2,3-Dimethylbutane & 8 & m-Ethyl toluene & 16 & Diacetone alcohol & 12 \\
\hline n-Heptane & -2 & p-Ethyl toluene & 0 & Propylene glycol & 0 \\
\hline 2-Methylhexane & 11 & 5-Ethyl-m-xylene & 64 & Ethylene glycol & 2 \\
\hline 3-Methylhexane & 7 & 3,5-Diethyl toluene & 37 & & \\
\hline n-Octane & -9 & Styrene & -18 & Other oxygenated VOC & \\
\hline n-Nonane & -9 & & & Methyl formate & 0 \\
\hline n-Decane & -4 & Oxygenated VOC & & Methyl acetate & 2 \\
\hline n-Undecane & -7 & & & Ethyl acetate & 8 \\
\hline n-Dodecane & -9 & Aldehydes & & n-Propyl acetate & 19 \\
\hline \multirow[t]{2}{*}{ Cyclohexane } & 28 & Formaldehyde & 74 & i- Propyl acetate & 5 \\
\hline & & Acetaldehyde & 35 & n-Butyl acetate & 7 \\
\hline Alkenes & & Propionaldehyde & -31 & s-Butyl acetate & 18 \\
\hline Ethene & 100 & Butyraldehyde & -28 & t-Butyl acetate & 1 \\
\hline Propene & 118 & 1-Butyraldehyde & 4 & Diethyl ether & 66 \\
\hline 1-Butene & 49 & Valeraldehyde & -8 & Methyl t-butyl ether & 16 \\
\hline cis-2-butene & 143 & Acryladehyde & 3 & Diisopropyl ether & 52 \\
\hline trans-2-butene & 161 & Methacrylaldehyde & -21 & tert-Butyl ethyl ether & 17 \\
\hline Isobutene & 112 & Crotonaldehyde & -17 & Methyl proxitol & 31 \\
\hline 1-Pentene & 35 & Benzaldehyde & -95 & Methyl glycol & 26 \\
\hline cis-2-Pentene & 87 & & & Ethyl glycol & 37 \\
\hline trans-2-Pentene & 88 & Ketones & & n-Butoxypropanol & 30 \\
\hline 2-methyl-1-Butene & 94 & Acetone & -1 & & \\
\hline 3-methyl-1-Butene & 55 & Butanone & 4 & Halogenated VOC & \\
\hline 2-methyl-2-Butene & 187 & Pentanone & 5 & Methylchloride & -2 \\
\hline 1-Hexene & 42 & 3-Pentanone & -2 & Methylene chloride & -1 \\
\hline cis-2-Hexene & 63 & Ethyl 1-propyl ketone & 10 & Chloroform & -2 \\
\hline trans-2-Hexene & 63 & Methyl n-butyl ketone & -6 & Methylchloroform & 0 \\
\hline \multirow[t]{3}{*}{ 2,3-Dimethyl but-2-ene } & 214 & Ethyl n-propyl ketone & 1 & Tetrachloroethane & 1 \\
\hline & & Methyl 1-butyl ketone & 27 & Trichloroethane & 11 \\
\hline & & Methyl t-butyl ketone & 6 & Vinyl chloride & 69 \\
\hline Alkynes & & Cyclohexanone & 27 & 1,2-Dichloroethane & 0 \\
\hline \multirow[t]{3}{*}{ Ethyne } & 1 & & & 1,1-Dichloroethene & 43 \\
\hline & & Organic acids & & 1,2-Dichlropropane & 0 \\
\hline & & Ethanoic acid & 8 & 1,1-Dichloroethane & 0 \\
\hline BVOC & & Propanoic acid & 6 & Chloroethane & 1 \\
\hline Isoprene & 102 & & & 1,1,2,2-Tetrachloroethane & 1 \\
\hline 1, 3-Butadiene & 105 & & & 1,1,2-Trichloroethane & -1 \\
\hline$\alpha$-pinene & 78 & & & cis-1,2-Dichloroethene & 19 \\
\hline$\beta$-pinene & 71 & & & trans-1,2-Dichloroethene & 17 \\
\hline
\end{tabular}

Similar to the patterns seen in earlier work, the POCPs of alkanes (-9 to 28) and oxygenated organic compounds ( 0 to 66 , excluding the more reactive aldehydes) had relatively low POCP values. The group of aromatic POCP values $(0-65)$ was generally lower than in pervious studies, with only trimethyl benzene having a POCP value above 90 . As in previous studies, the alkenes $(35-214)$ showed high POCP values 
(Jenkin et al., 1997, 2003; Saunders et al., 2003; Derwent et al., 2007; Cheng et al., 2010, 2013). Figure 1 gives a comparison of the Perth POCP values with those of the UK (Europe).

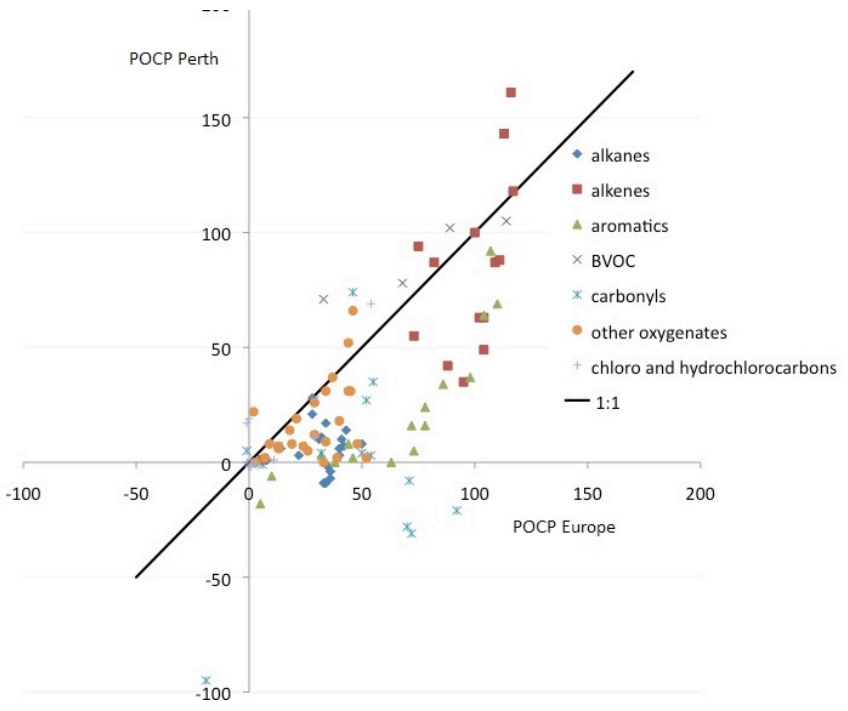

For most VOC the Perth POCP values are lower than the 1:1 line (Shown to guide the comparison) and a linear fit of the data gives $\mathrm{r}^{2}=0.78$. However, those VOC that are generally more reactive; some alkenes, BVOC, and aldehydes have POCP values that are comparable with the UK. The pattern differs to that seen in previous comparisons of the PRD and HK with the UK, which show a general trend of having similar or comparatively higher POCP values (Cheng et al., 2010, 2013). A direct comparison between the USA and UK POCP values has a linear relationship $\left(\mathrm{r}^{2}=0.82\right.$, data not shown), with the USA noticeably having POCP values higher (by $\sim 10$ ) for the other oxygenated VOC group, than those determined for Perth.

Figure 1. POCPs for Perth, WA vs UK (Europe), Derwent et al., 2007)

POCPs are a composite where both the emissions mass loading (region specific) as well as the atmospheric reactivity of the individual VOC is taken into consideration. They are useful for identifying important VOCs in the development of region-specific $\mathrm{O}_{3}$ episodes. Analyzing the relative POCP VOC-ranking across all studies shows variability in many cases, however features in the overall similarities reveal the following:

- Alkanes $(n=21)$. The methyl pentanes and hexanes, and 2,3-dimethyl butane rank in the top 10 across all studies, though in the USA and Perth i-butane is much higher ranked (joint $1^{\text {st }}$ and $2^{\text {nd }}$ ), than the PRD, HK and UK, where it is placed in the bottom 6. Ethane and propane are in the bottom 4 ranked except for the USA and Perth, where they rank higher than the longer straight chain hydrocarbons (C9-C12).

- Alkenes $(n=21)$. Ethene the reference VOC for POCP calculations is placed almost half way except for in the PRD where it ranked $15^{\text {th }}$. The 2-butenes, 2-pentenes and propene rank in the top 7 across all studies, except for Perth where the 2-pentenes were ranked $11^{\text {th }}$ and $12^{\text {th }}$, while 2-methyl-2-butene ranked above ethene in all regions except the UK. 1-hexene ranks in the bottom 5 expect for the UK where it is placed $13^{\text {th }}$.

- Aromatic compounds $(n=16)$. POCPs were not calculated for the USA. Across the other regions $1,3,5-$ trimethyl benzene, 1,2,4-trimethyl benzene, and 5-ethyl-m-xylene ranked in the top 4, while toluene ranked between $9^{\text {th }}$ and $12^{\text {th }}$. Ethyl and propyl benzene were in the bottom 5, with propyl benzene always lower then toluene. Benzene, due it its chemical stability came at the bottom in all regions.

- Carbonyls $(n=19)$. Acetaldehyde and formaldehyde were ranked in the top 4 across all regions except for the UK, where they were placed $5^{\text {th }}$ and $9^{\text {th }}$ respectively, preceded by the C3-C5-n-aldehydes. Overall ketones are known to be less reactive in the atmosphere, and they generally ranked below the aldehydes. However, methyl-1-butyl ketone was the highest ranked ketone across all regions, placed from $5^{\text {th }}$ to $7^{\text {th }}$. Acetone was ranked in the bottom 2 except for Perth where it ranked $12^{\text {th }}$ above the C3-C5-n-aldehydes.

- Other Oxygenated Compounds $(\mathrm{n}=38)$. In general the organic acids, esters and formates ranked below the ethers and alcohols. Diethyl ether ranked in the top 3. Cyclohexanol ranked in the top 5 except for the USA where it was placed $9^{\text {th }}$, and ethyl glycol ranked in the top 6 . t-Butyl acetate was ranked in the bottom 3 and methyl acetate was ranked in the bottom 5 across all regions.

- Halocarbons $(n=18)$. The saturated halocarbons all have very low POCP values $(<20$, and predominantly less than 10), and as such are of only minor significance in ground level ozone formation. However, the unsaturated halocarbons, have POCP values comparable with the higher ranked alkanes and other oxygenated compounds, and should be considered in ozone control strategies. Hence vinyl chloride and the chloroethenes rank in the top 4 across all regions, except for in the UK, where the chloroethenes are placed $6^{\text {th }}$ and $8^{\text {th }}$. Methyl chloroform is the lowest ranked chlorinated compound across all regions.

Ranking the VOC by the highest 50 POCP values from all studies (data taken for the UK from Derwent et al., 2007 (here defined as northwest Europe given the similarity in emissions profile with the UK), PRD from Cheng et al., 2012, HK from Cheng et al., 2013 and USA from Derwent et al., 2001), shows a dominance of alkenes and aromatic compounds, and 25 of these two VOC classifications are common across the studies (Table 2). Of the other VOC, only formaldehyde and acetaldehyde rank highly, with their highest position in the different regions ranking being $15^{\text {th }}(\mathrm{HK}$, Perth) and 5 th $(\mathrm{HK})$ respectively. 
Table 2. The 33 compounds (including isomers) common to the VOC ranked with highest 50 POCP values across all regions.

\begin{tabular}{|l|l|}
\hline Alkene VOC & Aromatic VOC \\
\hline Ethene & o,m,p-Xylene \\
\hline Propene & p-Ethyl toluene \\
\hline 1-Butene & 5-Ethyl-m-xylene \\
\hline 3-Methyl-1-butene & 3,5-Diethyl toluene \\
\hline 2-Methyl-2-butene & 1,3,5-Trimethylbenzene \\
\hline 2-Methyl-1-butene & 1,2,4-Trimethylbenzene \\
\hline cis/trans-2-Butene & Oxygenated VOC \\
\hline cis/trans-2-Pentene & Formaldehyde \\
\hline 1-Pentene & Acetaldehyde \\
\hline cis/trans-2-Hexene & Propionaldehyde \\
\hline 1-Hexene & Butyraldehyde \\
\hline Isoprene & Valeraldehyde \\
\hline 1,3-Butadiene & Methyl 1-butyl ketone \\
\hline Vinyl chloride & Diethyl ether \\
\hline & Cyclohexanol \\
\hline
\end{tabular}

A few other oxygenated compounds are also common to the top 50 POCP ranked VOC from all regions (Table 2). All occur in the lower half of the ranked lists, except for diethyl ether, which is placed at rank 19 in Perth. These other compounds include the more reactive aldehydes and alcohols though positions vary across the studies. Each region was found to have specific VOC that ranked differently to the other regions top 50 lists. For the UK it is the highest ranked alkane 2,3-dimethyl butane, (rank position 42), and for Asia (PRD and HK) chloroethene and some higher alkanes; methyl hexane and the $\mathrm{C} 9$ and $\mathrm{C} 10$ n-alkanes, (all below rank position 41), while diethyl ether ranked 34 in the PRD and 39 in HK respectively. Direct comparison with the USA cannot be made as no aromatic POCPs were calculated in that study, however here again diethyl ether ranks at position 20, and valeraldehyde has its highest ranked place at 26. Perth and the USA both have diisopropyl ether ranked at position 24. Although these other VOC influence the ozone formation in that specific region, their relatively low ranking positions has them placed (mostly) below the 15 VOC with highest POCP values. The top 15 ranked VOC across all the regions include only alkenes and aromatic compounds and these will have the most impact on ozone formation. Acetaldeyhe is an exception, which as mentioned above, ranks at position 5 in $\mathrm{HK}$. These VOC are ethene, propene, isoprene, the butenes and pentenes, and though some of the aromatic compounds do differ, only the trimethyl benzenes are consistently placed in the top 15 groups. Hence these are identified key VOC contributing to high ozone episodes in all locations, and should be targeted in emissions reduction strategies.

\section{CONCLUSIONS}

The POCP's calculated in this study for Perth, WA, is a region of notably lower levels of air pollution than all previous studies. Of note is that in general the POCP values for Perth are lower than those determined previously in the UK, USA and Asia. However, the relative ranking of the VOC by their POCP values for Perth and for the other available studies across the regions has increased our understanding of some key VOC species, in terms of their contributions to regional ozone pollution. Despite different geographic spatial domains across 4 continents, with consequently differing meteorology and emissions (VOC and NOx), leading also to differing temporal high ozone duration (from single day and multiday developments, to multiple peak days) at the receptors, this study has demonstrated that a few key alkene and aromatic VOC can be identified as high ozone contributors in all locations. Other VOC that influence ozone in specific regions were found to generally rank low in the highest 50 POCP groups, however the region specific ranking of formaldehyde, acetaldehyde and diethyl ether should also be taken into consideration. Given the commonality of the identified key VOC with the much more highly polluted airsheds also shows that the determination of POCP's for Perth has provided insightful intercomparison; using the POCP ranking, to identify key anthropogenic emitted VOC, that will most likely continue to be significant contributors to high ozone events, as the regions population and development grows. The study provides further support that the POCP methodology has considerable potential for application in policy development. It is of interest because of the ongoing and significant increase of episodic high ozone levels in rapidly developing regions of the world, making the need for practical abatement policies substantial.

\section{REFERENCES}

ABS, (2013) Australian Bureau of Statistics, 3218.0 - Regional Population Growth, Australia.: http://www.abs.gov.au/ausstats/abs@.nsf/mf/3218.0

Cheng, H.R., Guo, H., Saunders, S.M., Lam, S.H.M., Jiang, F., Wang, X.M., Simpson, I.J., Blake, D.R., Louie, P.K.K., Wang, T.J. (2010). Assessing photochemical ozone formation in the Pearl River Delta with a photochemical trajectory model. Atmospheric Environment 44, 4199-4208.

Cheng, H.R., Saunders, S.M., Guo, H., Louie' P.K.K., Jiang' F. (2013) Photochemical trajectory modeling of ozone concentrations in Hong Kong, Environmental Pollution, 180, 101-110.

Cope, M. and Ischtwan, J. (1995). Final report: Perth photochemical smog study, airshed modeling component, Environmental Protection Authority of Victoria, Australia 
Curtis, A.R. and Sweetenham W.P. (1987). FACSIMILE release H user's manual. AERE report R11771 (HMSO), London

DEC, Department of Environment and Conservation (2005), 2004 Western Australia Air Monitoring Report, Perth, WA. Technical series 122. ISBN : 1920947876

DEC, Department of Environment and Conservation, Western Australia (2012a). : http://www.dec.wa.gov.au/pollution-prevention/air-quality.html

DEC, Department of Environment and Conservation (2012b), 2011 Western Australia Air Monitoring Report, Perth, WA. : http://www.dec.wa.gov.au/pollution-prevention/air-quality/publications.html

Derwent, R.G., Jenkin, M.E., Saunders, S.M. (1996). Photochemical ozone creation potentials for a large number of reactive hydrocarbons under European conditions. Atmospheric Environment 30, 181-199.

Derwent, R.G., Jenkin, M.E., Saunders, S.M., Pilling, M.J. (1998). Photochemical ozone creation potentials for organic compounds in northwest Europe calculated with the MCM. Atmospheric Environment 32, 2429-2441.

Derwent, R.G., Jenkin, M.E., Saunders, S.M., Pilling, M.J. (2001). Characterization of the reactivities of volatile organic compounds using a MCM. Journal of the Air \& Waste Management Association 51, 699707.

Derwent, R.G., Jenkin, M.E., Passant, N.R., Pilling, M.J. (2007). Reactivity based strategies for photochemical ozone control in Europe. Environmental Science and Policy, 10, 445-453

Evtyugina, M.G., Pio, C., Nunes, T., Pinho, P.G., Costa, C.S. (2007). Photochemical $\mathrm{O}_{3}$ formation at Portugal West Coast under sea breeze conditions assessed by MCM model. Atmospheric Environment 41, 2171-2182

Jenkin, M.E. (2008). Trends in ozone concentration distributions in the UK since 1990: Local, regional and global influences. Atmospheric Environment 42, 5434-5445.

Jenkin, M.E., Saunders, S.M., Pilling, M.J. 1997. The tropospheric degradation of volatile organic compounds: A protocol for mechanism development. Atmospheric Environment 31, 81-104.

Jenkin, M.E., Saunders, S.M., Wagner, V., Pilling, M.J., 2003. Protocol for the development of the Master Chemical Mechanism, MCM v3 (Part B): tropospheric degradation of aromatic volatile organic compounds. Atmospheric Chemistry and Physics 3, 181-193.

Lim, S.S., Vos, T., Flaxman, A.D., Danaei, G., Shibuya, K., Adair-Rohani, H., Al-Mazroa, M.A., et al. (2013). A comparative risk assessment of burden of disease and injury attributable to 67 risk factors and risk factors clusters in 21 regions, 1990-2010 The Lancet, 380, 2224-2260.

Madronich, S. (2012). NCAR/ACD TUV: Tropospheric Ultraviolet \& Visible Radiation Model, http://cprm.acd.ucar.edu/Models/TUV/MCPA

MCPA, (2011). : http://www.mcpa-software.com/facsimileframe.html

NPI, National Pollutant Inventory (2007). : http://www.npi.gov.au/, Australia

Ostro, B. (2004) Outdoor air pollution: assessing the environmental burden of disease at national and local levels. Environmental Burden of Diseases Series, No. 5, World Health Organization, Geneva

Pinho, P. G., Lemos, L.T., Pio, C.A., Evtyugina, M.G., Nunes, T.V., Jenkin, M.E. (2009). Detailed chemical analysis of regional-scale air pollution in western Portugal using an adapted version of MCM v3.1. Science of the Total Environment 407(6): 2024-2038

Saunders, S.M., Jenkin, M.E., Derwent, R.G., Pilling, M.J. (2003). Protocol for the development of the Master Chemical Mechanism, MCM v3 (Part A): tropospheric degradation of non-aromatic volatile organic compounds. Atmospheric Chemistry and Physics 3, 161-180.

Sillman, S. (1999). The relation between ozone, $\mathrm{NO}_{\mathrm{x}}$ and hydrocarbons in urban and polluted rural environments. Atmospheric Environment 33, 1821-1845

SKM, Sinclair Knight Merz (2003). Aggregated emissions inventory of NPI substances for the Bunbury regional airshed, Western Australia; for the NPI database. WV02428:R41RJBFR, 1-128.

Srebot, V., Gianicolo, E. A. L., Rainaldi, G., Trivella, M. G. and Sicari, R. (2009). Ozone and cardiovascular injury. Cardiovascular ultrasound (7); 1476-7120, doi: 10.1186/1476-7120-7-30

USEPA (2006). US-Environmental Protection Agency, National ambient air quality standards for particulate matter: proposed rule. Federal Register, 71, 2620-2708

Walker, H.L., Derwent, R.G., Donovan, R., Baker, J. (2009). Photochemical trajectory modeling of ozone during the summer PUMA campaign in the UK West Midlands. Science of the Total Environment 407, 2012-2023.

WHO (2004). Health aspects of air pollution. World Health Organization, Copenhagen, WHO Regional Office for Europe. : http://www.euro.who.int/_data/assets/pdf_file/0003/74730/ E83080.pdf

WHO (2006). Global update 2005. Air quality guidelines for particulate matter, ozone, nitrogen dioxide and sulfur dioxide.: http://www.euro.who.int/_data/assets/pdf_file/0005/78638/E90038.pdf

Zardin, E. (2012). Long-term monitoring of trace volatile organic compounds in ambient air of Western Australia by proton transfer reaction-mass spectrometry (PTR-MS). PhD thesis, UWA. 